\title{
An Ontology-based Profile for Learner Representation in Learning Networks
}

\author{
http://dx.doi.org/10.3991/ijet.v9i3.3305 \\ Kalthoum Rezgui, Hedia Mhiri and Khaled Ghédira \\ Higher Institute of Management, Tunis, Tunisia
}

\begin{abstract}
In the context of lifelong learning, learning networks are emerged as alternative and feasible integrated models that merge pedagogical, organizational, and technological perspectives to support and promote the provision of lifelong learning opportunities. Among the significant issues that arise when setting up a learning network is the question of how to support communication between repositories that employ different schemes for describing learner profiles. To guarantee correct interpretation, a semantic common metadata schema is required. This paper aims to propose an ontological structure for representing a learner profile that augments it with semantics and provides a common vocabulary for the exchange of the different learner's characteristics that can be presented in a learner model. The proposed structure is based on different learner information with respect to well-known learner model specifications. Besides, it reuses terms from well-developed Semantic Web vocabularies which make it semantic web compliant and integrates different domain taxonomies and subject taxonomies that are used as ranges for particular concepts' slots.
\end{abstract}

Index Terms - Student modeling, lifelong learning, Semantic Web, ontology, learning networks.

\section{INTRODUCTION}

For the past fifteen years or so, lifelong learning [1] has become an important topic of academic and policy debates on promoting new partnerships, new curricula and new assessment methods. Lifelong learning can be considered as a continuous education process that covers any form of learning (i.e. formal, non-formal and informal) undertaken throughout the life and leading to fostering of continuous development and improvement of knowledge, skills and competencies. To promote the provision of lifelong learning opportunities, learning networks [2-4] are emerged as alternative and feasible integrated models that merge pedagogical, organizational, and technological perspectives. A learning network is defined as a set of persons, institutions, software agents and learning resources that are mutually interconnected and supported by information and communication technologies [5]. Many problems arise when setting up a learning network, such as the issue of how to support communication between repositories that employ different schemes for describing learner profiles. In fact, a semantic common metadata schema is required in order to ensure correct interpretation. This paper discusses how to improve learner profiles with semantics by building an ontology and how this latter can be employed to support communication between software agents and to provide personalized access to learning resources in learning networks. The issue presented above lies within the scope of student modeling that can be defined as the process of acquiring various kinds of knowledge about the student [6]. The output of this process is a student model that contains all the information about a student ranging from biographic data to interaction preferences and formal/informal experiences. Several adaptive systems $[7,8]$ rely on a student modeling component in order to provide personalized content, services, learning flows and paths according to specific student's needs.

In the field of user modeling, [9-11] pointed out the advantages of using ontologies for learner modeling. The ontology schema that we propose is structured according to well-developed learner model specifications, namely, the IEEE PAPI [12] and the IMS LIP [13]. It also reuses terms from well-developed Semantic Web vocabularies, such as Dublin Core [14] and FOAF [15] which make it semantic web compliant. Besides, it integrates different domain taxonomies for referencing particular values in a slot of a concept. In particular, we used the Bloom's taxonomy of educational objectives [16], the learning style taxonomy of [17] and the RDF binding of the ACM Computing Classification System (CCS) [18]).

The remainder of this paper is organized as follows: in Section 2, we present two of the most important learner profile proposals. A mapping between the structures of the these specifications is also drawn up in this section. Other relevant user profile models are presented in Section 3. In Section 4, we present a comparative study of the surveyed learner models in order to determine the basic components of the learner profile ontology. Section 5 describes in detail the process of the Learner Profile ontology construction.

\section{USER MODELING SPECIFICATIONS}

In this section, we present the most important specifications that focus on representing and managing user profiles in learning environments: the IMS Learner Information Package (IMS-LIP) [13] and the Public and Private Information (PAPI) for Learners (PAPI Learner) specification [12].

\section{A. The IMS Learner Information Package (LIP) specification}

The LIP IMS/GLC [12] specification provides a standard means for recording information about learners. It is designed to allow information about learners, including their progress to date and awards received, to be transferred between different software applications.

In this specification, the Learner Information is separated into eleven main categories of information that are: Identification, QCL, Accessibility, Activity, Goal, Competency, Interest, Transcript, Affiliation, Securitykey, and 
Relationship. These categories represent the primary data structures that are required to support learner information i.e., only the required information needs to be stored and packaged. Figure 1 shows the underlying logical data structures for the learner information package.

\section{B. The IEEE Public and Private Information for Learners ((PAPI Learner) specification}

The PAPI Learner specification [12] aims to support the storage, retrieval, searching, and exchange of learner data between different systems. This specification partitions the learner information into six main information types that support extension:

- Learner Contact Information: describes information related to administration.

- Learner Relations Information: stores information about the learner's relationships to other users of learning systems, such as teachers and other learners.

- Learner Security Information: stores information about the learner's security credentials, e.g. passwords, private keys, public keys, biometrics.

- Learner Preference Information: describes preference information intended to improve humancomputer interactions and the automatic adaptation and personalization of systems to the specific needs of the learner.

- Learner Performance Information: is about the learner's history, current work, or future objectives. PAPI Performance information is primarily created and used by learning technology components to provide improved or optimized learning experiences.

- Learner Portfolio Information: is a representative collection of the learner's works or references to them that is intended for presentation and evidencing of his achievements and abilities.

The information model proposed by the PAPI Learner Specification describes a minimal subset of all possible types of information about the learner. It represents one of the first proposals offering a framework that organizes the learner's data.

In Figure 3, we illustrate the mapping between the eleven core data structures of the IMS-LIP and the six structures of the IEEE PAPI Learner. As we can see, both the IEEE PAPI learner and the IMS LIP specifications provide the following elements:

- Identification: personal information for a specific learner. This includes data such as: name, address, contact information.

- Relation: information about the learner's relationship to other persons or about memberships of professional organizations.

- Security: a description of the set of passwords, security keys, and credentials assigned to the learner for transactions with learner information systems and services.

- Goal: a description of the personal objectives and aspirations of the learner.

- Accessibility and preferences: the cognitive, physical and technical preferences of the learner, eligibility, disability and language capabilities.

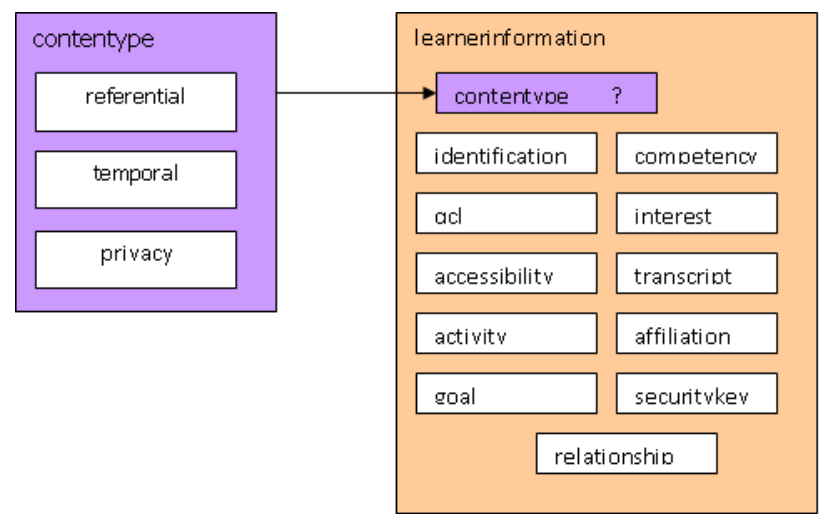

Figure 1. The principle Learner Information Package (LIP) data structures [13]

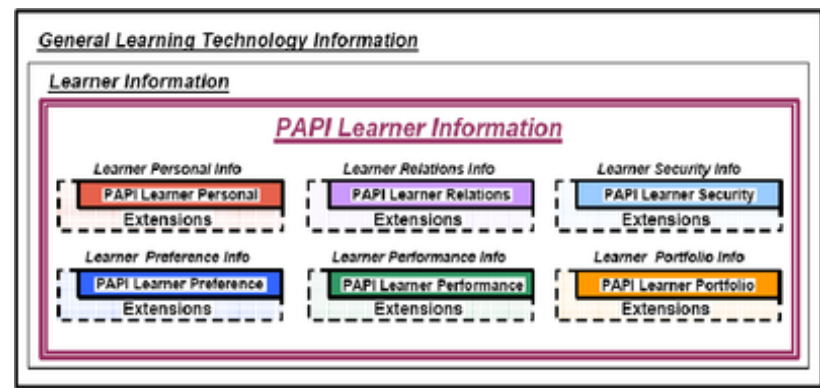

Figure 2. Learner Information Groups in the IEEE PAPI Learner Model [12]

- Achievements and learner experience: a description of the learner's measured performance, awarded certification, acquired competencies, produced works, undertaken activities, and summary of academic achievements.

- Interest: information about hobbies and other recreational activities of the learner.

On the other hand, as we can see in Figure 3, the data models associated to these specifications are not sufficiently complete to cover all the learner's data that can be exchanged between e-learning systems, particularly those related to pedagogical aspects, such as records of the set of information that are gathered at the end of pedagogical activities performed within a learning course or that describe the set of learning steps, activities and choices which characterize the learner's educational path. However, as discussed in [19] educational learner data is an important element of a learner model. Yet, the IMS-LIP specification forms a first attempt to model the learner's pedagogical data. In fact, in a part of the "Activity" category, we find the educational activities related to the learner.

Finally, the binding of the IEEE PAPI and the IMS LIP specifications is described in the XML language. However, XML is not appropriate for semantic interoperability since it just describes grammars. Accordingly, it is not possible "to recognize a semantic unit from a particular domain because XML aims at document structure and imposes no common interpretation of the data contained in the document" [20]. 


\section{IEEE PAPI Learner}

IMS-LIP

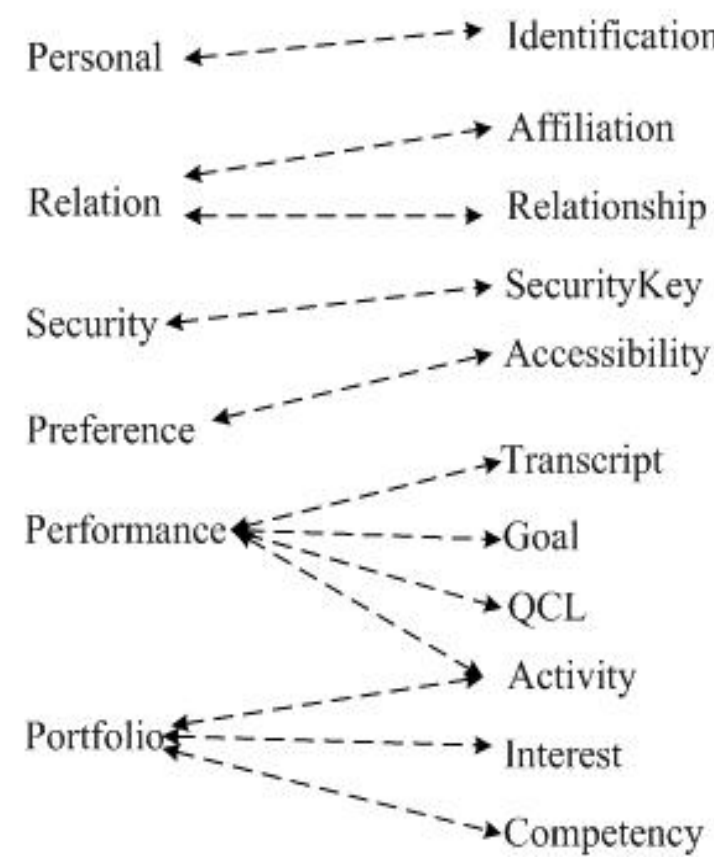

Figure 3. Mapping between the structures of IEEE PAPI and IMS-LIP

To summarize, the learner models proposed by IEEE PAPI and IMS-LIP represent a basic step toward categorizing and structuring the users' data that needs to be exchanged between various e-learning systems.

\section{Other RELEVANT USER Profile Models}

Dolog and Nejdl [11] proposed a user profile that was developed for the ELENA project. The learner model was based on subsets of both PAPI and IMS-LIP specifications and describes a learner with the following five categories: (1) Identification that keeps information about the student (such as name, email, address), (2) Other User Features that records information about the student' preferences, their goals and interests, (3) Study Performance that describes the student's performance, portfolio, and certification, (4) Human Resource Planning (HRP) that records information about the organization in which the student is a member, and (5) Calendar (which is not inherited from PAPI or IMS LIP) that keeps details about events, appointments and meetings the learner has to attend.

Keenoy et al. [21] developed a user profile model for the SeLeNe project that includes some elements from PAPI and IMS-LIP specifications particularly for describing the learner's personal information, qualifications, interests, learning goals and competencies. The data model is extended with new specific elements that are needed by SeLeNe to provide personalized search and access to learning objects. The new elements aim to record data about the learning objectives, learning style preference and educational history of a learner as well as notifications of changes carried out in the metadata repository.

Oubahssi and Grandbastien [19] suggested a learner model that aims to improve interoperability and exchange of learners' pedagogical data between e-Learning systems. In particular, the model extends the IMS-LIP data model with new categories (namely, "Profile", "Metadata", "Educational path", and "Commentaries") and new elements. The Profile category describes the set of information that are gathered at the end of pedagogical activities performed within a learning career. The "Educational path" category describes the set of steps, activities, and choices that characterize the educational path of a learner. The main advantage of the proposed model is that it preserves compatibility with existing standards whilst enabling the exchange of pedagogical data about learners. This kind of data has not been sufficiently taken into account in the IEEE PAPI and IMS-LIP specifications. The model is also extensible but it lacks many details regarding the descriptions of new categories (i.e. size, value space, data types, etc.). Besides, [19] did not clearly indicate how equivalence of the new vocabularies with the IMS-LIP will be defined.

Wei and Yan [22] also proposed a user profile model to facilitate the development of personalized e-learning systems. The proposed model extends the IEEE PAPI Learner specification with the following new categories: (1) Goal that records the user's subjective sensation, i.e. whether he wants to start a new learning experience or to continue the last study, (2) Session information that keeps data about sessional factors, such as preparatory time that the student can get for studying, knowledge level of a user, and network situation, and (3) Learning Objects Record that stores the learning objects that the user has already studied and their associated metadata.

Panagiotopoulos et al. [23] proposed an ontology-based student model that facilitates exploitation of the semantics of student models by intelligent tutoring systems (ITS). The developed ontology is a combination of IEEE PAPI Learner and IMS-LIP specifications and the results of an empirical study conducted on a sample of students in order to identify the learner characteristics and their categories. It defines a set of upper level classes that enable describing students (Student), their performance during the educational process (StudentCourseInformation), learning activities performed for the current academic year (StudentCurrentActivity), their demographic data and their preferences regarding interaction with the e-learning system.

\section{COMParative STUdy OF THE LEARNERs Models}

In this section, we present a comparative study of the different learner models that have been described above. The seven models are compared against the learner's features taxonomy proposed by [24] since it covers most possible features that can describe a learner. We have refined this taxonomy by adding a new category, called "Pedagogical" based on the findings of the study conducted by [19] aiming to improve the interoperability of learner data between different e-learning systems. This category serves to capture pedagogical information, such as the set of pedagogical activities carried out by the learner within a learning curriculum, the sequence of learning units that he must achieved, etc. The taxonomy of [24] classifies the learner's characteristics into eight categories: Personal data, Relation, Goals, Achievements and Learner history, Accessibility and preferences, Interests, Context, and Security. Besides, each category is further divided into sub categories. Table 1 presents the comparison of the different user profile models. We use the following notations for the comparison: ' + ' for full support, 'P' for partial support, ' $\mathrm{X}$ ' for ability to be extended and a gap for no support. 
TABLE I.

COMPARATIVE STUDY BETWEEN SURVEYED MODELS ON USER PROFILE MODELING

\begin{tabular}{|c|c|c|c|c|c|c|c|c|}
\hline Categories & Sub categories & PAPI & LIP & $\begin{array}{c}\text { Oubahssi } \\
\text { and Grandbastien, } \\
2007\end{array}$ & $\begin{array}{l}\text { Wei and } \\
\text { Yan, 2009 }\end{array}$ & $\begin{array}{c}\text { Dolog and } \\
\text { Nejdl, } 2003\end{array}$ & $\begin{array}{l}\text { Panagiotopoulos } \\
\text { et al., } 2012\end{array}$ & $\begin{array}{l}\text { Keenoy et } \\
\text { al., } 2005\end{array}$ \\
\hline \multirow{2}{*}{$\begin{array}{c}\text { Personal } \\
\text { Information }\end{array}$} & General & + & + & + & + & + & + & + \\
\hline & Description & & & & & & & \\
\hline \multirow{2}{*}{ Relations } & Formal & & & & & & & \\
\hline & Informal & + & & & + & & & \\
\hline Security & & + & + & + & + & + & & \\
\hline Goal & & & + & + & + & + & + & + \\
\hline \multirow{5}{*}{$\begin{array}{c}\text { Experience } \\
\text { and } \\
\text { Achievements }\end{array}$} & Performance & + & + & + & + & + & + & + \\
\hline & Certification & + & + & + & + & + & & + \\
\hline & Competency & + & + & + & & + & & + \\
\hline & Portfolio & + & + & $\mathrm{P}$ & + & + & & + \\
\hline & Transcript & $\mathrm{X}$ & + & + & + & & & \\
\hline \multirow{6}{*}{$\begin{array}{l}\text { Preferences } \\
\text { and } \\
\text { Accessibility }\end{array}$} & Language & + & + & + & + & $\mathrm{P}$ & + & + \\
\hline & Learning styles & + & + & + & & & + & + \\
\hline & Technical & & + & + & + & & + & \\
\hline & Physical & & + & + & + & & $\mathrm{P}$ & \\
\hline & Eligibility & + & + & + & & + & + & \\
\hline & Disability & + & + & + & & + & + & \\
\hline Interest & & & + & + & & + & + & + \\
\hline \multirow[b]{2}{*}{ Context } & Affiliation & & + & + & & + & + & \\
\hline & $\begin{array}{c}\text { Organiza- } \\
\text { tion/Group }\end{array}$ & & + & & & & & \\
\hline \multirow{2}{*}{ Pedagogical } & Profile & & & + & & & & \\
\hline & Educational Path & & & + & & & & \\
\hline
\end{tabular}

Based on the comparison table presented above, we observe that all the models include representation of learners' Personal Information and Performance. Besides, most of them contain representations of Goal, Language and learning styles preferences, Security, Affiliation, and Interest. We also notice that the only user model that considers the exchange of learner pedagogical information, in particular profiles and educational paths, is the one proposed by [19]. However, the advantage of modeling such information in a user profile is twofold: it provides (1) improved interoperability of learner data by including pedagogical ones and (2) optimized adaptation of educational paths and contents to the learner's needs.

On the other hand, by comparing the purpose of development of these learner models, we note that [22] and [23] focus on learning goals and interaction preferences of the learner, hence they are best used to facilitate personalization in adaptive e-Learning systems. IEEE PAPI [12], [11] and [21] focus on the performance, achievements and previous experience of the learner. These features are also considered important in building e-Learning systems that deliver personalized learning contents according to the learner's requirements.

\section{Construction of the Learner Profile Ontology}

In this section, we describe the process of the Learner Profile ontology construction. The major steps of this process are based on the ontology building methodology "Methontology" [25]. The construction process consists of five phases as follows:
- Phase 1: Requirements Specification.

- Phase 2: Conceptualization.

- Phase 3: Formalization.

- Phase 4: Implementation.

- Phase 5: Evaluation.

\section{A. Specification}

This phase consists in drawing a formal document of requirements specification. In this document, we describe the ontology to be built through the following aspects:

- Domain: learner profile modeling for distance learning.

- Purpose: to enable a formal representation of learners' data and exchange of these data with other learning applications.

- Users: this aspect presents the set of users who can exploit the ontology. In our case, these are learners, teachers and content authors.

Information source: the sources of information on which we based are mainly well-known specifications for user modeling $[12,13]$. Besides, we considered the research works of $[11,19,21-23]$ and the projects that deal with user modeling and personalization to avoid misinterpretation of the official specifications, such as, the ELENA project, the DELOS project, and the SeLeNe project. Moreover, we used well-known Web vocabularies, such as, Dublin Core [14] and FOAF [15], and domain taxonomies and subject taxonomies for referencing partic- 
ular values in a slot of a concept. In particular, we employed the Bloom's taxonomy of educational objectives [16], the learning style taxonomy of [17] and the RDF binding of the ACM Computing Classification System (CCS) [18]) that are used as ranges for particular concepts' slots in the Learner Profile Ontology. In what follows, we present an overview of the projects mentioned above:

\section{- ELENA Project: the ELENA project} (http://www.elena-project.org/) aims to propose personalization, openness, and interoperability solutions in the context of smart spaces for learning. One of the central design elements of these spaces is a learner profile that includes information about the user's learning history, preferences, and goals. This learner model was created based on the IEEE PAPI and IMS-LIP specifications.

- DELOS Project: the DELOS network (http://www.delos.info/) aims to develop a reference model for digital library management systems that meets the requirements of the next generation of digital library technologies and to implement a prototype of that reference model. A Learner Information Model has been developed based on elements from both IEEE PAPI and IMS-LIP specifications. We adopted this model for the representation of preferences and learning Objectives of the learner.

- SeLeNe Project: the Self E-Learning Networks project (http://www.dcs.bbk.ac.uk/selene/) has developed a User Profile for SeLeNe users in order to support personalized search of learning objects. The proposed user profile integrates elements from existing learner profile schemes (i.e. IEEE PAPI [12], IMS-LIP [13] and IMS-RDCEO [26]) and adds new elements where these schemes fail to be expressive enough to support SeLeNe's personalization requirements. We adopted the SeLeNe user profile schema for the representation of information regarding the history of searches and learning objects access.

- Scope: this aspect determines a priori the list of ontology terms among which we can quote: learner, goal, preference, performance, competency, educational level, learning style, credential list, learning provider, knows, etc.

\section{B. Conceptualization}

Once most of knowledge are acquired, the conceptualization phase consists in organizing and structuring those knowledge using intermediate semi-formal representations which are easy to understand and independent of any implementation language. This phase contains several stages which are:

\section{1) Construction of concepts glossary}

This glossary contains the definitions of all terms related to the field (concepts, attributes, relations). Table II provides only a list of some terms used in the ontology.

\section{2) Construction of concept hierarchies}

In this stage, we construct the diagrams of concepts classification which organize the ontology concepts in a hierarchy expressing the "is $A$ " relationship (see Figure 4).
The relationship "isA" between classes defines that, the class $C 1$ is a subclass of the class $C 2$, if and only if any instance of the class $C 1$ is an instance of class $C 2$.

\section{3) Construction of binary relations diagrams}

In this stage, we construct the diagram of binary relations. Figure 5 presents a graphical representation of the concepts of the Learner Profile ontology and the relationships between them.

TABLE II.

TABLE OF TERMS GLOSSARY

\begin{tabular}{|l|l|}
\hline \multicolumn{1}{|c|}{ Concept } & \multicolumn{1}{c|}{ Description } \\
\hline Personal Information & describes biographic and demographic data. \\
\hline Goal & $\begin{array}{l}\text { describes the personal objectives and aspirations } \\
\text { of the learner. }\end{array}$ \\
\hline Performance & $\begin{array}{l}\text { describes the learner's measured performance, } \\
\text { e.g. grades. }\end{array}$ \\
\hline QCL & $\begin{array}{l}\text { describes any qualifications, certifications, } \\
\text { licenses or degrees awarded to the learner. }\end{array}$ \\
\hline Competency & $\begin{array}{l}\text { describes the set of knowledge, skills and abili- } \\
\text { ties the learner has acquired during learning. }\end{array}$ \\
\hline Transcript & $\begin{array}{l}\text { Describes an institutionally-based summary of } \\
\text { academic achievement. }\end{array}$ \\
\hline Portfolio & $\begin{array}{l}\text { describes the list of work products and projects } \\
\text { produced by the learner. }\end{array}$ \\
\hline Language & $\begin{array}{l}\text { describes the learner's preferences regarding the } \\
\text { language of the learning objects content and } \\
\text { presentation. }\end{array}$ \\
\hline Language level & $\begin{array}{l}\text { describes the language levels used to assess } \\
\text { language proficiency. }\end{array}$ \\
\hline Learning style & $\begin{array}{l}\text { describes the learner's preferred cogni- } \\
\text { tive/learning style. }\end{array}$ \\
\hline Interest & $\begin{array}{l}\text { describes hobbies and other recreational activi- } \\
\text { ties. }\end{array}$ \\
\hline Security & $\begin{array}{l}\text { describes the set of passwords, security keys, and } \\
\text { credentials assigned to the learner. }\end{array}$ \\
\hline Educational level & $\begin{array}{l}\text { describes the learner's preferences regarding the } \\
\text { education level. }\end{array}$ \\
\hline $\begin{array}{l}\text { Educational Learn- } \\
\text { ing provider }\end{array}$ & $\begin{array}{l}\text { describes the author or organization making } \\
\text { available the learning objects. }\end{array}$ \\
\hline Learning planner & $\begin{array}{l}\text { describes the persons that develops learning } \\
\text { designs. }\end{array}$ \\
\hline$(\ldots)$ & $(\ldots)$ \\
\hline
\end{tabular}

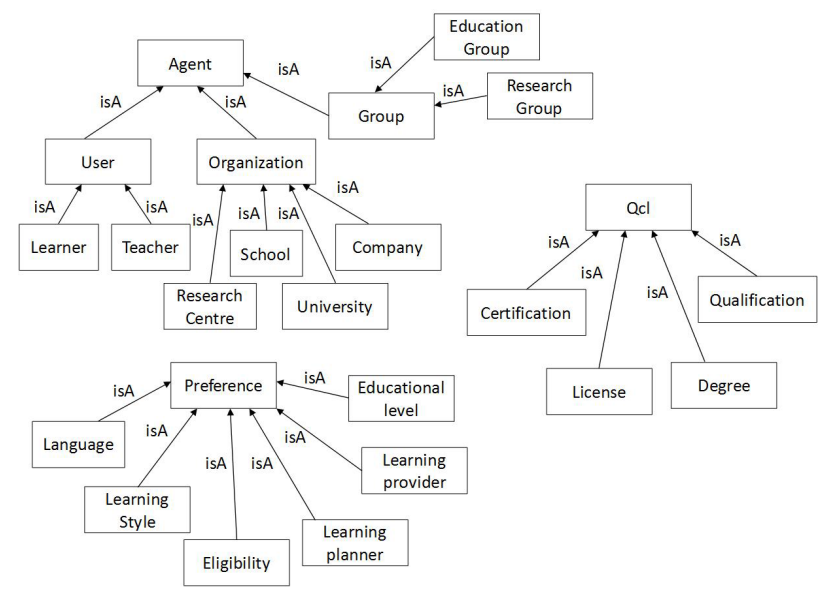

Figure 4. The hierarchies of concepts 


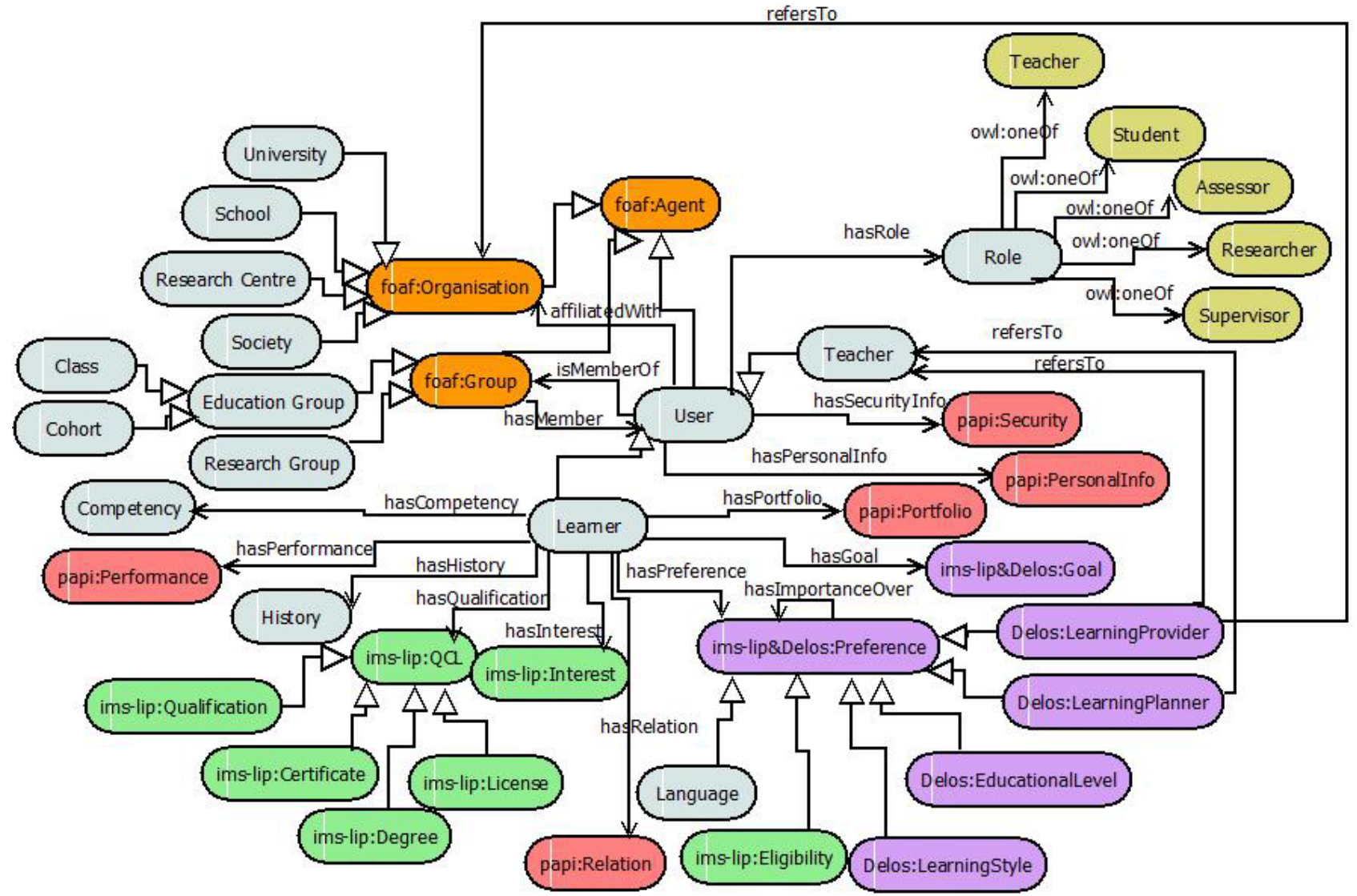

Figure 5. Graphical representation of the Learner Profile Ontology

\section{4) Dictionary of concepts}

In this stage, we present a formal description of concepts that were presented in the class hierarchy. This process consists in creating a dictionary of concepts in which we specify, for every concept, the following information: the properties, the parent, and the relationships. Table III presents the dictionary of concepts of the learner profile ontology:

TABLE III.

DICTIONARY OF CONCEPTS OF THE LEARNER PROFILE ONTOLOGY

\begin{tabular}{|c|c|c|c|}
\hline Concept & Role & Parent & Attributes \\
\hline Agent & - & Thing & - \\
\hline User & $\begin{array}{l}\text { hasRole, hasPersonalInfo, } \\
\text { hasSecurityInfo, isMemberOf, } \\
\text { affiliatedWith }\end{array}$ & Agent & $\begin{array}{l}\text { first_name, } \\
\text { last_name, fami- } \\
\text { ly_name, } \\
\text { birthday, age, } \\
\text { email, address, } \\
\text { telephone }\end{array}$ \\
\hline Teacher & & User & - \\
\hline Learner & $\begin{array}{l}\text { hasGoal, hasInterest, hasPrefer- } \\
\text { ence, hasPerformance, hasQual- } \\
\text { ification, hasRelation, hasPort- } \\
\text { folio, hasHistory, hasCompe- } \\
\text { tency }\end{array}$ & - & - \\
\hline Group & hasMember & Agent & - \\
\hline $\begin{array}{l}\text { Organiza- } \\
\text { tion }\end{array}$ & - & Agent & - \\
\hline Goal & isAssociatedWith & Thing & $\begin{array}{l}\text { goal_date, } \\
\text { goal_type, } \\
\text { goal_priority, } \\
\text { goal_status }\end{array}$ \\
\hline
\end{tabular}

\begin{tabular}{|c|c|c|c|}
\hline $\begin{array}{l}\text { Learning } \\
\text { Objective }\end{array}$ & $\begin{array}{l}\text { isAssociatedWith, learning } \\
\text { objective_topic }\end{array}$ & Thing & $\begin{array}{l}\text { learn- } \\
\text { ing_objective_ver } \\
\text { b, learning _- } \\
\text { objec- } \\
\text { tive_annotation } \\
\end{array}$ \\
\hline $\begin{array}{l}\text { Learning } \\
\text { Style }\end{array}$ & - & Thing & $\begin{array}{l}\text { learn- } \\
\text { ing_style_value, } \\
\text { learning_- } \\
\text { style_taxonomy }\end{array}$ \\
\hline $\begin{array}{l}\text { Prefer- } \\
\text { ence }\end{array}$ & $\begin{array}{l}\text { prefLanguage, prefLearn- } \\
\text { ingStyle, prefEducationalLevel, } \\
\text { prefLearningProvider, pre- } \\
\text { fLearningPlanner, associat- } \\
\text { ed_Eligibility, hasImportance- } \\
\text { Over }\end{array}$ & Thing & - \\
\hline $\begin{array}{l}\text { Perfor- } \\
\text { mance }\end{array}$ & $\begin{array}{l}\text { associated_Certificate, associ- } \\
\text { ated_Portfolio, learn- } \\
\text { ing_competency, learn- } \\
\text { ing_experience, issued_from }\end{array}$ & Thing & $\begin{array}{l}\text { performance_id, } \\
\text { performance_- } \\
\text { coding, perfor- } \\
\text { mance_metric, } \\
\text { perfor- } \\
\text { mance_value, } \\
\text { granularity, } \\
\text { issued_date, } \\
\text { begin, finish }\end{array}$ \\
\hline Interest & - & Thing & $\begin{array}{l}\text { interest_type, } \\
\text { inter- } \\
\text { est_description }\end{array}$ \\
\hline Language & $\begin{array}{l}\text { has_listening_level, } \\
\text { has_reading_level, } \\
\text { has_spoken_interaction_level, } \\
\text { has_spoken_production_level,h } \\
\text { as_writing_level }\end{array}$ & Thing & $\begin{array}{l}\text { language_code, } \\
\text { language_name }\end{array}$ \\
\hline$(\ldots)$ & $(\ldots)$ & $(\ldots)$ & $(\ldots)$ \\
\hline
\end{tabular}




\section{5) Tables of binary relations}

The binary relations are represented as properties that link a concept to another. For each concept whose source is in the concepts classification tree, we specify: its name, its description, the source concept, the target concept, the cardinality, and the name of the inverse relationship. Table IV shows the binary relations of the Learner Profile ontology.

\section{6) Tables of attributes (or slots)}

Data properties are properties that take their values from predefined datatypes (Integer, Float, String, Boolean,
Date, etc.). For each property, we specify: its name, description, domain, and range. Table $\mathrm{V}$ shows the table of concepts' attributes of the Learner Profile ontology.

\section{7) Table of logical axioms}

The Table VI contains definitions of concepts using logical expressions that are asserted to be always true. Particularly, we define for each axiom its description in natural language, the concept to which the axiom refers and the logical expression. The following table presents some of the specified axioms.

TABLE IV

TABLE OF BINARY RELATIONS OF THE LEARNER PROFILE ONTOLOGY

\begin{tabular}{|l|l|c|c|c|c|c|}
\hline \multicolumn{1}{|c|}{ Relationship } & \multicolumn{1}{|c|}{ Description } & $\begin{array}{c}\text { Source Concept } \\
\text { (s) }\end{array}$ & $\begin{array}{c}\text { Target Concept } \\
\text { (s) }\end{array}$ & $\begin{array}{c}\text { Card } \\
\text { S }\end{array}$ & $\begin{array}{c}\text { Card } \\
\text { T }\end{array}$ & $\begin{array}{c}\text { Inverse Rela- } \\
\text { tionship }\end{array}$ \\
\hline affiliatedWith & $\begin{array}{l}\text { connects a user to one or several organizations to which he is } \\
\text { affiliated }\end{array}$ & User & Organization & $1 \ldots \mathrm{N}$ & $1 \ldots \mathrm{N}$ & \\
\hline hasRole & $\begin{array}{l}\text { connects a user to the role that he plays within the organization } \\
\text { to which he is affiliated }\end{array}$ & User & Role & $1 . . \mathrm{N}$ & 1 & \\
\hline hasMember & indicates the members of a group & Group & User & $1 . . \mathrm{N}$ & $1 . . \mathrm{N}$ & isMemberOf \\
\hline hasGoal & connects a learner to the learning goals he wants to achieve & Learner & Goal & 1 & $1 \ldots \mathrm{N}$ & isGoalOf \\
\hline hasQualification & $\begin{array}{l}\text { connects a learner to the qualifications, certifications, licenses } \\
\text { and degrees that he has been awarded from recognized authori- } \\
\text { ties }\end{array}$ & Learner & QCL & 1 & $1 \ldots \mathrm{N}$ & $\begin{array}{c}\text { isQualifica- } \\
\text { tionOf }\end{array}$ \\
\hline hasPerformance & $\begin{array}{l}\text { connects a learner to the list of learning experiences that he has } \\
\text { taken part in and their associated measured performance }\end{array}$ & Learner & Performance & 1 & $1 . . \mathrm{N}$ & $\begin{array}{c}\text { isPerforman- } \\
\text { ceOf }\end{array}$ \\
\hline hasPortfolio & $\begin{array}{l}\text { connects a learner to the record of work products and projects } \\
\text { that he has produced during a learning experience }\end{array}$ & Learner & Portfolio & 1 & $1 . . \mathrm{N}$ & belongsTo \\
\hline$(\ldots)$ & $(\ldots)$ & $(\ldots)$ & $(\ldots)$ & $(\ldots)$ & $(\ldots)$ & $(\ldots)$ \\
\hline
\end{tabular}

TABLE $\mathrm{V}$.

TABLE OF CONCEPTS' ATTRIBUTES OF THE LEARNER PROFILE ONTOLOGY

\begin{tabular}{|c|c|c|c|c|}
\hline Attribute & Description & Domain & Range & Value space \\
\hline goal type & the type of goal & Goal & String & Work, Educational, Professional \\
\hline goal_status & recorded status of the goal & Goal & String & $\begin{array}{l}\text { Active, Inactive, Retired, Complet- } \\
\text { ed, In-Progress, Pending, Expired }\end{array}$ \\
\hline interest description & The description of interest & Interest & String & \\
\hline interest_type & the type of interest & Interest & String & Recreational, Vocational, Domestic \\
\hline performance_coding & $\begin{array}{l}\text { the coding system used to evaluate the performance } \\
\text { level of the learner }\end{array}$ & Performance & String & \\
\hline performance_metric & $\begin{array}{l}\text { the metrics used to evaluate the performance level of the } \\
\text { student }\end{array}$ & Performance & String & \\
\hline qcl_title & The title of the qualification, certification or license & QCL & String & \\
\hline qcl_organisation & $\begin{array}{l}\text { The organization responsible for the awarding of the } \\
\text { qualification, certification, or license }\end{array}$ & QCL & String & \\
\hline language_name & the name of the language & Language & String & \\
\hline learning style value & a taxonomic value of the learning style & Learning Style & String & \\
\hline learning_style_taxonomy & $\begin{array}{l}\text { a reference to the schema/ taxonomy used to describe } \\
\text { the learning style values }\end{array}$ & Learning_Style & String & \\
\hline$(\ldots)$ & $(\ldots)$ & $(\ldots)$ & $(\ldots)$ & $(\ldots)$ \\
\hline
\end{tabular}

TABLE VI.

TABLE OF CONCEPT AXIOMS OF THE LEARNER PROFILE ONTOLOGY

\begin{tabular}{|l|l|l|}
\hline \multicolumn{1}{|c|}{ Concept } & \multicolumn{1}{c|}{ Axiom } & \multicolumn{1}{c|}{ Description } \\
\hline Agent & $\forall(\mathrm{X})$, Agent $(\mathrm{X}) \Rightarrow$ User $(\mathrm{X}) \vee$ Organisation $(\mathrm{X}) \vee$ Group $(\mathrm{X})$ & An agent is a user or an organization or a group. \\
\hline User & $\forall(\mathrm{X})$, User $(\mathrm{X}) \Rightarrow$ Learner $(\mathrm{X}) \vee$ Teacher $(\mathrm{X})$ & A user is a learner or a teacher. \\
\hline QCL & $\begin{array}{l}\forall(\mathrm{X}), \mathrm{QCL}(\mathrm{X}) \Rightarrow \text { Qualification }(\mathrm{X}) \vee \text { Certification }(\mathrm{X}) \vee \text { License }(\mathrm{X}) \\
\mathrm{V} \text { Degree }(\mathrm{X})\end{array}$ & $\begin{array}{l}\text { Each QCL is either a qualification, or a certification, or a } \\
\text { license, or a degree. }\end{array}$ \\
\hline Qualification & $\begin{array}{l}\forall(\mathrm{X}), \text { Qualification }(\mathrm{X}) \Rightarrow \mathrm{QCL}(\mathrm{X}) \wedge(\neg \text { Certification }(\mathrm{X}))^{\wedge}(\neg \text { License } \\
(\mathrm{X}))^{\wedge}(\neg \text { Degree }(\mathrm{X}))\end{array}$ & $\begin{array}{l}\text { The concepts Qualification, Certification, License, and } \\
\text { Degree are incompatible. }\end{array}$ \\
\hline Preference & $\begin{array}{l}\forall(\mathrm{X}), \text { Preference }(\mathrm{X}) \Rightarrow \text { Language }(\mathrm{X}) \vee \text { Learning_Style }(\mathrm{X}) \vee \text { Learn- } \\
\text { ing_Provider }(\mathrm{X}) \vee \text { Learning_Planner }(\mathrm{X}) \vee \text { Educational_Level }(\mathrm{X}) \vee\end{array}$ \\
$\begin{array}{l}\text { Eligibility }(\mathrm{X}) \\
\text { learning style, or a preferred learning provider, or a pre- } \\
\text { ferred learning planner, or a preferred educational level, or } \\
\text { any eligibility. }\end{array}$ \\
\hline$(\ldots)$ & $(\ldots)$ & $(\ldots)$ \\
\hline
\end{tabular}


PAPER

AN ONTOLOGY-BASED PROFILE FOR LEARNER REPRESENTATION IN LEARNING NETWORKS

TABLE VII.

DEFINITION OF THE LEARNER PROFILE ONTOLOGY'S CONCEPTS (IN TBOX)

\begin{tabular}{|c|c|c|}
\hline Concept & Definition & $\begin{array}{l}\text { Subsumption } \\
\text { Relation }\end{array}$ \\
\hline User & $\begin{array}{l}\text { User } \cap(=1 \text { identifier.String }) \cap(=1 \text { first_name.String }) \cap(=1 \text { last_name.String }) \cap(=1 \text { birth- } \\
\text { day.String }) \cap(=1 \text { address.String }) \cap(=1 \text { telephone.String }) \cap(=1 \text { email.String }) \cap(=1 \text { has- } \\
\text { Role.Role }) \cap(\geq 1 \text { hasSecurityInfo.Security }) \cap(=1 \text { hasPersonalInfo.Personal_Information }) \cap(\geq \\
1 \text { is-MemberOf.Group }) \cap(\geq 1 \text { affiliatedWith.Affiliation })\end{array}$ & User $\subseteq$ Agent \\
\hline Learner & $\begin{array}{l}\text { User } \cap(\geq 1 \text { hasGoal.Goal }) \cap(\geq 1 \text { hasPreference.Preference }) \cap(\geq 1 \text { hasQualification.QCL }) \cap \\
(\geq 1 \text { hasInterest.Interest }) \cap(\geq 1 \text { hasPortfolio.Portfolio }) \cap(\geq 1 \text { hasCompetency.Competency }) \cap \\
(\geq 1 \text { hasHistory.History }) \cap(\geq 1 \text { hasRelation.Relation })\end{array}$ & Learner $\subseteq$ User \\
\hline Goal & $\begin{array}{l}(=1 \text { goal_type.String }) \cap(=1 \text { goal_date.String }) \cap(=1 \text { goal_priority.String }) \cap(=1 \\
\text { goal_status.String }) \cap(\geq 1 \text { associated_Learning_Objective.Learning_Objective })\end{array}$ & Goal $\subseteq$ Thing \\
\hline Learning_Objective & $\begin{array}{l}(=1 \text { learning_objective_verb.String }) \cap \text { (=1learning_objective_annotation.String }) \cap(=1 \text { learn- } \\
\text { ing_objective_topic.Topic) }\end{array}$ & Learning_Objective $\subseteq$ Thing \\
\hline Learning_Style & $(=1$ learningstyle_value.String $) \cap(=1$ learningstyle_taxonomy.String $)$ & Learning_Style $\subseteq$ Thing \\
\hline Preference & $\begin{array}{l}(=1 \text { prefLearningStyle.Learning_Style }) \cap(=1 \text { prefLanguage.Language }) \cap(=1 \text { prefLearningPro- } \\
\text { vider.Learning_Provider }) \cap(=1 \text { prefLearning_Planner.Learning_Planner }) \cap \\
(=1 \text { prefEducationalLevel.Educational_Level }) \cap(=1 \text { associated_Eligibility.Eligibility })\end{array}$ & Preference $\subseteq$ Thing \\
\hline$(\ldots)$ & $(\ldots)$ & $(\ldots)$ \\
\hline
\end{tabular}

\section{Formalization}

In this phase, we use the Description Logics formalism [27] to formalize the conceptual model obtained in the conceptualization phase. We define the concepts of our ontology using the constructors offered by description logics to provide structured and formal descriptions to concepts. These definitions are illustrated in Table 7 with the subsumption relations that exist between concepts. Besides, we define the roles by giving the couples of concepts sources and targets of each one, and/or by specifying its inverse role. Table 8 presents the definitions of some roles of our ontology.

TABLE VIII.

DEFINITION OF THE LEARNER PROFILE ONTOLOGY'S ROLES (IN TBOX)

\begin{tabular}{|c|c|c|}
\hline Roles & $\begin{array}{c}\text { Couple (Domain, } \\
\text { Range) }\end{array}$ & Inverse Role \\
\hline hasRole & (User, Role) & - \\
\hline affiliatedWith & (User, Organization) & - \\
\hline hasMember & (Group, User) & isMemberOf \\
\hline hasHistory & (Learner, History) & - \\
\hline hasQualification & (Learner, Qualification) & isQualificationOf \\
\hline hasGoal & (Learner, Goal) & isGoalOf \\
\hline isAssociatedWith & $\begin{array}{l}\text { (Learning_Objective, } \\
\text { Goal) }\end{array}$ & $\begin{array}{l}\text { associat- } \\
\text { ed_Learning_Objectiv } \\
\text { e }\end{array}$ \\
\hline hasPerformance & (Learner, Performance) & isPerformanceOf \\
\hline hasImportanceOver & (Preference, Preference) & - \\
\hline hasPortfolio & (Learner, Portfolio) & - \\
\hline$(\ldots)$ & $(\ldots)$ & $(\ldots)$ \\
\hline
\end{tabular}

\section{Implementation}

The implementation phase consists in encoding the formal ontology obtained in the formalization phase in an ontology representation language that makes it operational. We choose the Web Ontology Language (OWL) [28], which is a W3C standard for all the semantic features that it offers and which are richer than those of DAML+OIL. Besides, OWL is a part of the Description Logics formalism and its semantic can be defined via a transcription to SHIQ Description Logic. The process of ontology con- struction was supported by the Protégé tool (http://protege.stanford.edu/) which is an ontology and a knowledge base editor. It provides a graphical user interface (GUI) for ontology editing and implementation and it enables to generate the OWL code. To develop our ontology using the Protégé editor, we followed the following steps:

\section{1) Creation of classes and class hierarchy}

The first step as illustrated in figure 6 gives the hierarchy of the Learner Profile ontology's concepts. The class hierarchy is composed of classes (Agent, Goal, Interest, Performance, Preference, etc.) and of subclasses (Learner, License, University, Language, etc.).

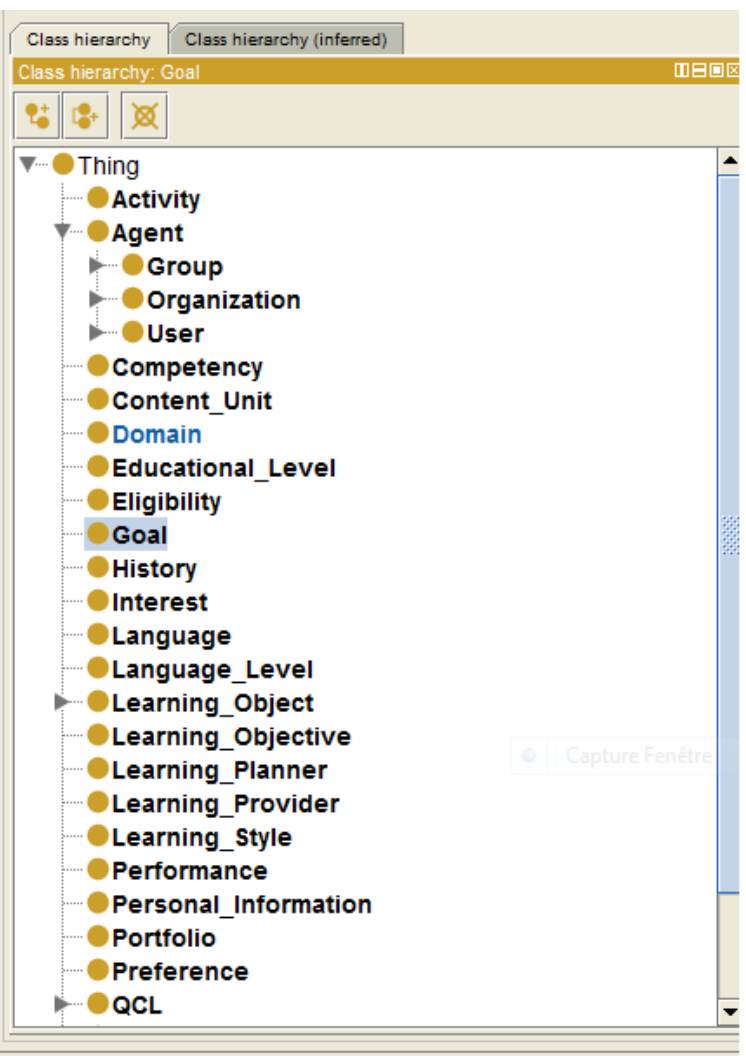

Figure 6. Class hierarchy of the Learner Profile Ontology 


\section{2) Creation of object properties}

The second step consists in defining the relationships between the classes and their descriptions (see Figure 7): domain (rdfs:domain), co-domain (rdfs:range), inverse relationship (owl:inverseOf), annotation, and other characteristics (functional, inverse functional, transitive, symmetric, etc.).

\section{3) Creation of data properties}

In the step 3, we create for each class the set of attributes that characterize it and we specify their descriptions (see Figure 8): domain (rdfs:domain), codomain (rdfs:range), value space, and annotation.

\section{4) Creation of instances of the ontology}

In the step 4, we create the instances (individuals) of the ontology's classes. Figure 9 shows the instances of the Language_Level class.

\section{E. Evaluation}

We used the Racer (Renamed ABox and Concept Expression Reasoner) reasoner [29] to verify the consistency and the classification of the developed ontology. Consistency checking consists in determining if a class can be instantiated or not. Classification checking is invoked between classes and consists in inferring a new hierarchy of classes from the definitions of these latter. It enables to remove inconsistency between the classes definitions.

\section{CONCLUSION}

In this paper, we have described the development of an ontology for the modeling of learner profiles particularly for learning networks learners. Besides, we have presented a comparative study between the different proposals dealing with user modeling which gives us a general view of the different learner's characteristics that can be included in the Learner Profile Ontology. The proposed ontology is structured based on the most important learner model specifications and, hence it supports reusability, syntactic and semantic interoperability. We plan as a future work to propose an effective approach for supporting advanced personalization services in learning networks that can be derived from the Learner Profile Ontology we have developed, such as personalized access to learning resources and activities, and personalized learning path generation tailored to learners' individual competencies.

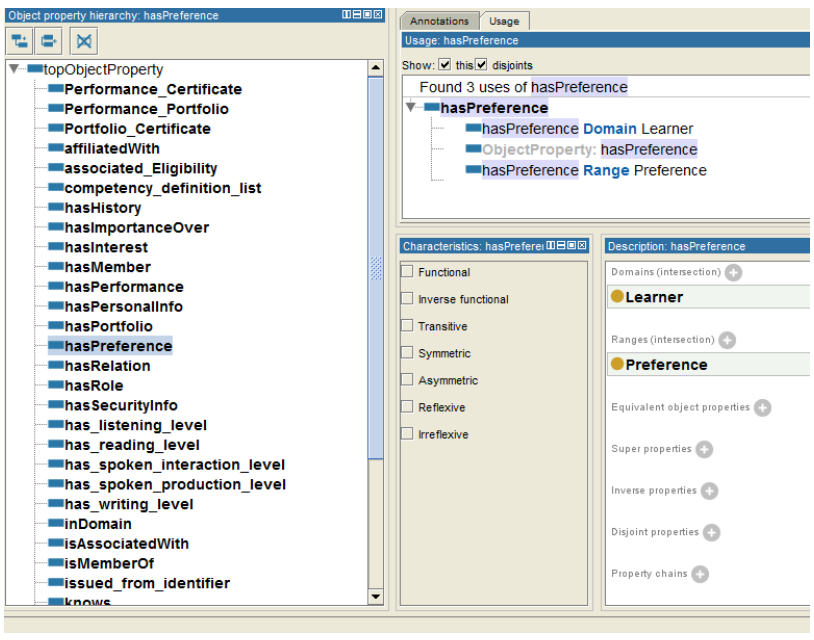

Figure 7. Object properties of the Learner Profile Ontology

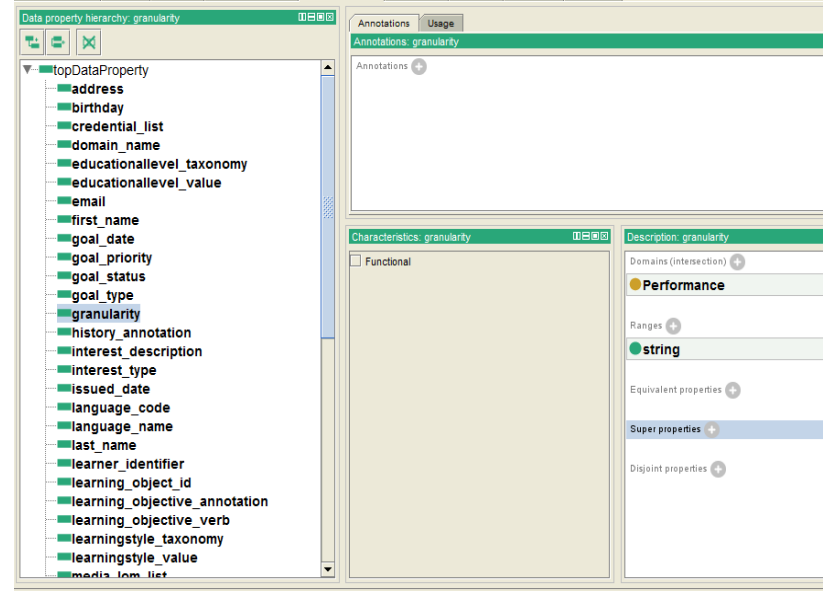

Figure 8. Data properties of the Learner Profile Ontology

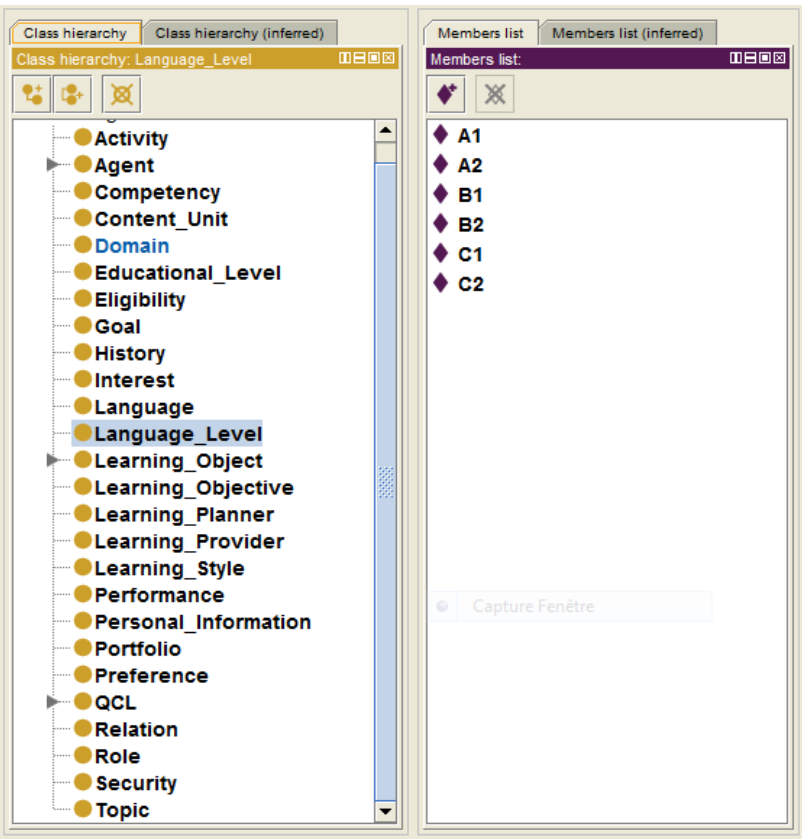

Figure 9. Instances of the the Language_Level class

\section{REFERENCES}

[1] S. Beer. (2007). Lifelong learning: debates and discourses. Paper submitted to NIACE's Lifelong Learning Inquiry. Available: http://www.niace.org.uk/lifelonglearninginquiry/docs/Conceptuali singLLL.pdf.

[2] R. Koper, E. Rusman, and P. Sloep, "Effective Learning Network," in Lifelong Learning in Europe, 2005, pp. 18-27.

[3] R. Koper and C. Tattersall, "New directions for lifelong learning using network technologies," British Journal of Educational Technology, vol. 35, no. 6, pp. 689-700, 2004. http://dx.doi.org/10.1111/j.1467-8535.2004.00427.x

[4] P. B. Sloep, "Building a Learning Network through Ad-Hoc Transient Communities," in the International Conference on Computer Mediated Social Networking, 2008, pp.

[5] Y. Miao, M. Klink, M., J. Boon, P. Sloep, and R. Koper, "Toward an integrated competence-based system supporting lifelong learning and employability: Concepts, model, and challenges," in the 8th International Conference on Advances in Web Based Learning, Berlin, Heidelberg, 2009, pp. 265-276.

[6] D. Paneva, "Use of Ontology-Based Student Model in semanticoriented access to the knowledge in digital libraries," in the Open Workshop Semantic Web and Knowledge Technologies Applications, 2006, pp. 31-41. 
[7] C. D. B. Boyle. and A. O. Encarnacion, "Metadoc: An Adaptive Hypertext Reading System," User Modeling and User-Adapted Interaction, vol. 4, no. 1, pp. 1-19, 1994. http://dx.doi.org/10.1007/ BF01142355

[8] P. Brusilovsky and E. Millán, "User models for adaptive hypermedia and adaptive educational systems," in The adaptive web: methods and strategies of web personalization, P. Brusilovsky, A. Kobsa, and W. Nejdl, Eds. Springer-Verlag, Berlin, Heidelberg, 2007, pp. 3-53.

[9] W. Chen and R. Mizoguchi, "Communication Content Ontology for Learner Model Agent in Multi-Agent Architecture," in AIED99 Workshop on Ontologies for Intelligent Educational Systems, 1999, pp. 95-102.

[10] J. Kay, "Ontologies for reusable and scrutable student model," position paper, in AIED99 Workshop on Ontologies for Intelligent Educational Systems, 1999, pp. 72-77.

[11] P. Dolog, and W. Nejdl, "Challenges and benefits of the semantic web for user modeling," in AH2003 Workshop at 12th Int'l WWW Conference, Budapest, Hungary, 2003.

[12] Draft Standard for Learning Technology - Public and Private Information (PAPI) for Learners (PAPI Learner) - Core Features, IEEE P1484.2.1/D8, 2001. Available: http://metadatastandards.org/Document-library/Meeting-reports/SC32WG2/200205-Seoul/WG2-SEL-042 SC36N0175 papi learner core feat ures.pdf.

[13] IMS Learner Information Packaging Information Model Specification, version 1.0, 2001. Available: http://www.imsglobal.org/ profiles/lipinfo01.html.

[14] Dublin Core Metadata Element Set, Version 1.1: Reference Description, 2003. Available: http://dublincore.org/documents/ 2003/02/04/dces/.

[15] FOAF Vocabulary Specification 0.98, 2010. Available: http://xmlns.com/foaf/spec/.

[16] L. W. Anderson. and D. R. Krathwohl, "A taxonomy for learning, teaching, and assessing: A revision of Bloom's taxonomy of educational objectives," Addison Wesley Longman, Inc, New York, 2001.

[17] R. Felder and L. Silverman, "Learning and teaching styles in engineering education," Engineering Education, vol. 78, no. 7, pp. 674-681, 1988.

[18] Brase, J. and Wolfgang, "Ontologies for eLearning," Tech. Rep., 2002.

[19] L. Oubahssi and M. Grandbastien, "From learner information packages to student models: Which continuum?" in ITS 2006, $\operatorname{LNCS~n}^{\circ} 4053$, Springer Verlag, 2006, pp. 288-297.
[20] S. Decker, S. Melnik, F. van Harmelen, D. Fensel, M. Klein, and J. Broekstra, "The Semantic Web: The roles of XML and RDF", IEEE Internet Computing, vol. 4, no. 5, pp. 63-67, 2000. http://dx.doi.org/10.1109/4236.877487

[21] K. Keenoy, M. Levene, and D. Peterson, "Personalisation and trails in self e-learning networks," selene working package 4 deliverable 4.2, 2005.

[22] X. Wei and J. Yan, "Learner profile design for personalized elearning systems," in the International Conference on Computational Intelligence and Software Engineering (CiSE 2009), 2009, pp. $1-4$.

[23] I. Panagiotopoulos, A. Kalou, C. Pierrakeas, and A. Kameas, "An ontology-based model for student representation in intelligent tutoring systems for distance learning," Artificial Intelligence Applications and Innovations, vol. 381, pp. 296-305, 2012. http://dx.doi.org/10.1007/978-3-642-33409-2_31

[24] A. Ounnas, I. Liccardi, H. C. Davis, D. E. Millard, and S. A. Whiter, "Towards a semantic modeling of learners for social networks," in International Workshop on Applications of Semantic Web Technologies for E-Learning (SW-EL), Dublin, Ireland, 2006, pp. 102-108.

[25] M. Fernandez, A. Gomez-Perez, and N. Juristo. N, "Methontology: from ontological art towards ontological engineering," in the AAAI97 Spring Symposium Series on Ontological Engineering, Stanford, USA, 1997, pp. 33-40.

[26] IMS Reusable Definition of Competency or Educational Objective Specification, version 1.0, 2002. Available: http://www.imsglobal. org/competencies/.

[27] F. Baader, I. Horrocks, and U. Sattler, "Description Logic," in Handbook of Knowledge Representation, F. van Harmelen, V. Lifschitz, and B. Porter, Eds., Elsevier, 2008, ch.. 3, pp. 135-180. http://dx.doi.org/10.1016/S1574-6526(07)03003-9

[28] D. L. McGuinness and F. V. Harmelen. (2004). OWL Web ontology language overview. Available: http://www.w3.org/TR/owlfeatures/, 2004.

[29] V. Haarslev and R. Möller, "Description of the RACER System and its Applications," in International Workshop on Description Logics (DL-2001), Stanford, USA, 2001.

\section{AUTHORS}

Kalthoum Rezgui, Hedia Mhiri and Khaled Ghédira are with the Higher Institute of Management, Tunis, Tunisia.

Submitted 02 November 2013. Published as re-submitted by the authors 18 May 2014. 